\title{
Comment on "Serum and synovial fluid levels of interleukin-17 in correlation with disease activity in patients with RA"
}

\author{
Liang-Ping Ye $\cdot$ Xue-Mei Zhan $\cdot$ Hua-Qing Hu
}

Received: 1 September 2011 /Accepted: 24 September 2011 /Published online: 18 October 2011

(C) Clinical Rheumatology 2011

\section{Dear Editor,}

We read with interest the article by Metawi et al. entitled "Serum and synovial fluid levels of interleukin-17 in correlation with disease activity in patients with RA" [1]. Their results showed that the elevated serum and synovial IL-17A levels in RA patients parallel the degree of disease activity and severity, which may highlight the usefulness of IL-17 (especially serum level) as a possible marker for more aggressive joint involvement and damage. It is an interesting study. However, the results of the study should be treated with caution.

Firstly, the sample size is relatively small and is therefore of limited power, which may weaken the conclusion of this study. Moreover, are the data normally distributed? If not, the nonparametric tests such as rank sum test and Spearman's rank correlation should be used, rather than the $t$ test, ANOVA, and Pearson's correlation test. Secondly, it would be better to recruit new-onset patients because the treatment may have influence on the serum and synovial fluid expression of cytokines. Thirdly, it would be more interesting to correlate the serum and synovial fluid levels of IL-17 with clinical manifestations of RA patients. Finally, were the patients with other coexisting complications excluded or not? For instance, RA patients complicated with SLE or other autoimmune diseases should be excluded from this study.

Collectively, the results of this study should be treated with caution. To reach a definitive conclusion, further

L.-P. Ye $(\bowtie) \cdot$ X.-M. Zhan $\cdot$ H.-Q. Hu

Physical Examination Center, The First Affiliated Hospital of Anhui Medical University,

218 Jixi Road,

Hefei, Anhui 230022, People's Republic of China

e-mail: yelp2008@163.com studies based on better design are needed. In spite of these, many previous studies have revealed that IL-17, the signature cytokine of the newly described $\mathrm{T}$ helper 17 (Th17) cell population, was implicated in the pathogenesis of numerous autoimmune diseases including RA [2-6]. Hopefully, IL-17 may prove to be a promising therapeutic target in RA. However, additional studies on animals in vivo and patients, respectively, are needed to further evaluate the pharmacotherapeutical potential of this strategy.

Disclosures None.

\section{References}

1. Metawi SA, Abbas D, Kamal MM, Ibrahim MK (2011) Serum and synovial fluid levels of interleukin-17 in correlation with disease activity in patients with RA. Clin Rheumatol 30(9):1201-1207

2. Zhao XF, Pan HF, Yuan H, Zhang WH, Li XP, Wang GH, Wu GC, Su H, Pan FM, Li WX, Li LH, Chen GP, Ye DQ (2010) Increased serum interleukin 17 in patients with systemic lupus erythematosus. Mol Biol Rep 37(1):81-85

3. Mei Y, Pan F, Gao J, Ge R, Duan Z, Zeng Z, Liao F, Xia G, Wang S, Xu S, Xu J, Zhang L, Ye D (2011) Increased serum IL-17 and IL-23 in the patient with ankylosing spondylitis. Clin Rheumatol 30 (2):269-273

4. Kohno M, Tsutsumi A, Matsui H, Sugihara M, Suzuki T, Mamura M, Goto D, Matsumoto I, Ito S, Suguro T, Sumida T (2008) Interleukin-17 gene expression in patients with rheumatoid arthritis. Mod Rheumatol 18(1):15-22

5. Chen DY, Chen YM, Chen HH, Hsieh CW, Lin CC, Lan JL (2011) Increasing levels of circulating Th17 cells and interleukin-17 in rheumatoid arthritis patients with an inadequate response to antiTNF-alpha therapy. Arthritis Res Ther 13(4):R126

6. Marder W, Khalatbari S, Myles JD, Hench R, Yalavarthi S, Lustig S, Brook R, Kaplan MJ (2011) Interleukin 17 as a novel predictor of vascular function in rheumatoid arthritis. Ann Rheum Dis 70 (9):1550-1555 